\title{
Factores genéticos del hospedero involucrados en la susceptibilidad y gravedad de la COVID-19.
}

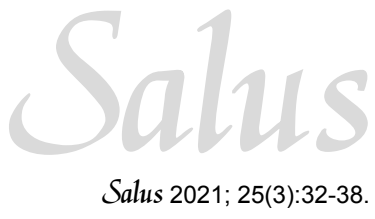

Host genetic factors involved in the susceptibility and severity of COVID-19.

dol https://doi.org/10.54139/salus.v25i3.130

Esmeralda Vizzi ${ }^{1}$ (D) Viviana Ramírez ${ }^{1}$ (D) Rita E. Rosales ${ }^{1}$ (D) José Luis Zambrano ${ }^{1}$ (D) Mercedes Fernández-Mestre (ID) $^{\text {(D) }}$

\section{RESUMEN}

Introducción: La infección por SARS-CoV-2 determina desde formas asintomáticas hasta manifestaciones muy graves de COVID-19 que pueden comprometer la vida. El impacto de la pandemia por COVID-19 plantea la necesidad de identificar los factores de riesgo que condicionan la variabilidad interindividual en la susceptibilidad a la infección por SARS-CoV-2, la fisiopatología y la progresión de la enfermedad. Varios autores sugieren que el componente genético juega un papel clave en la compleja interacción existente virus-hospedero, donde las diferencias poblacionales dirigen tal heterogeneidad. Métodos: Se realizó una revisión bibliográfica de la literatura científica, publicada hasta los momentos, relacionada con los marcadores biológicos que participan en la evolución de la infección por SARS-CoV-2 y los polimorfismos de moléculas potencialmente involucradas en la compleja interacción virus-hospedero. Hallazgos de interpretación: Numerosas evidencias señalan que variantes alélicas de genes que codifican para moléculas que actúan en las etapas tempranas de interacción del virus con la célula o en eventos que determinan la respuesta inmunitaria del hospedero, podrían favorecer la infección por SARS-CoV-2 o la gravedad de la enfermedad. El grupo sanguíneo $A B O$ pareciera jugar un papel en la inmunopatogénesis, mostrando los individuos de grupo $\mathrm{O}$ un menor riesgo a infectarse con SARS-CoV-2, aunque otros componentes del hospedero, genéticos, fisiológicos y metabólicos, como la expresión diferencial de receptores tipo toll, antígenos HLA, citocinas proinflamatorias, quimiocinas $u$ otros efectores de la respuesta inmunitaria innata y

${ }^{1}$ Laboratorio de Biología de Virus, Centro de Microbiología y Biología Celular, Instituto Venezolano de Investigaciones Científicas (IVIC). Carretera Panamericana Km 11, Caracas 1020-A, Edo. Miranda, Venezuela.

Laboratorio de Fisiopatología, Sección Inmunogenética. Centro de Medicina Experimental Miguel Layrisse, Instituto Venezolano de Investigaciones Científicas (IVIC). Caracas 1020-A, Edo. Miranda, Venezuela.

Autor de correspondencia: Esmeralda Vizzi (D)

E-mail: esmeralda.vizzi@gmail.com, evizzi@ivic.gob.ve

Recibido: 09-11-2021

Aprobado: 01-12-2021 adquirida, estarían también participando. Reflexiones finales: EI éxito y progresión de la infección viral hacia el desarrollo de una manifestación clínica y su gravedad dependen, en gran medida, de la interacción entre factores virales y la respuesta del hospedero, que a su vez está condicionada por factores genéticos, epigenéticos y comorbilidades preexistentes. La contribución del componente genético plantea la potencial aplicación de estrategias preventivas dirigidas, la identificación de blancos terapéuticos y el desarrollo de nuevos fármacos.

Palabras clave: SARS-CoV-2, COVID-19, susceptibilidad genética, gravedad

\section{ABSTRACT}

Background: SARS-CoV-2 infection ranges from asymptomatic forms to very serious manifestations of COVID-19 that can compromise life. The impact of the COVID-19 pandemic raises the need to identify the risk factors that determine interindividual variability in susceptibility to SARS-CoV-2 infection, pathophysiology and disease progression. Several authors suggest that the genetic component plays a key role in the complex virus-host interaction, where population differences are responsible for such heterogeneity. Methods: A scoping review of the literature published to date was carried out in order to learn about the biological markers that seem to affect the evolution of the SARS-CoV-2 infection and the genetic polymorphisms of molecules potentially involved in the complex virus-host interaction. Results: Numerous evidences indicate that allelic variants of genes encoding molecules working in the early stages of virus-cell interaction or during events that define the immune response of the host, could favor the infection and/or the disease severity by SARS-CoV-2. The ABO blood group seems to play a role in immunopathogenesis, with group $O$ individuals showing a lower risk of being infected with SARS-CoV-2, although other genetic, physiological and metabolic components of the host, such as the differential expression of toll-like receptors, HLA antigens, proinflammatory cytokines, chemokines or other effectors of the innate and acquired immune response would also be participating. Conclusions: The success and progression of the viral infection towards the development of clinical manifestations and the severity grade depend largely on the interaction between viral factors and the host's response, as well as seem to be conditioned by epigenetic factors and pre-existing comorbidities. The contribution of the genetic component raises the potential application of targeted preventive strategies, the identification of therapeutic targets and the development of new drugs.

Keywords: SARS-CoV-2, COVID-19, genetic susceptibility, disease severity

\section{Salus




\section{INTRODUCCIÓN}

A más de un año y medio desde el inicio de la pandemia, la COVID-19 sigue generando gran preocupación por el alto número de vidas que ha cobrado. Si bien en la mayoría de los casos cursa de forma asintomática o con síntomas, de leves a moderados, generalmente del tracto respiratorio superior, aproximadamente un $15 \%$ evoluciona hacia cuadros de neumonía con dificultad respiratoria aguda, y un $5 \%$ eventualmente desarrolla una insuficiencia respiratoria aguda grave, con choque séptico, falla multiorgánica y muerte.

La edad avanzada y las condiciones preexistentes, por ejemplo, cardiovasculares, pulmonares y enfermedades renales, han sido relacionadas con una mayor gravedad de la COVID-19 (1), y si bien las tasas de infección son similares para hombres y mujeres, se ha descrito una tasa promedio de letalidad de 1,7 veces mayor en los hombres (2). Los factores de riesgo asociados con la edad, género y existencia de patologías previas aún no explican del todo el amplio espectro de manifestaciones clínicas, así como sorprende la tasa de hospitalización de individuos más jóvenes y aparentemente sanos, a veces con cuadros clínicos particularmente graves, por lo que se sospecha que otros factores, principalmente genéticos, puedan condicionar la susceptibilidad a la infección por SARS-CoV-2, la gravedad de la COVID-19 o la emergencia de ciertas variantes virales.

Diversos estudios han intentado evaluar la relación entre la progresión de la infección por SARS-CoV-2 a enfermedad y las condiciones del hospedero. Los primeros resultados apuntan a que el componente genético juega un papel clave en la compleja interacción existente entre los factores de patogenicidad viral y la respuesta inmunitaria del hospedero, determinando el riesgo de infectarse o la gravedad de los síntomas.

El objetivo principal del presente trabajo es proporcionar información relacionada con los factores genéticos involucrados en la susceptibilidad a la infección por SARSCoV-2 y la evolución o progresión a COVID-19, y la potencial aplicación de este conocimiento.

\section{METODOLOGÍA}

Se realizó una revisión bibliográfica de la literatura científica publicada hasta el 28 de octubre 2021. La búsqueda bibliográfica se realizó en la base de datos de Medline a través de Pubmed (en inglés) usando las palabras claves "SARS-CoV-2" and "susceptibility", "COVID-19" and "host genetics", "genetic predisposition" and "COVID-19", o "COVID-19" and "ABO group". Para la selección de los artículos relacionados con la enfermedad se establecieron como criterios de inclusión estudios originales que incluyeran población con acertada infección por COVID-19, visibilizando aquellos con evidencia consistente.

\section{HALLAZGOS DE INTERPRETACIÓN}

Genética y susceptibilidad. Evidencias generadas durante brotes de gastroenteritis y en individuos voluntarios han indicado que las personas con grupo sanguíneo tipo $O$ desarrollan gastroenteritis causadas por norovirus (NoV) con un riesgo 11 veces mayor que las de grupo sanguíneo
B (3) y un riesgo doble de infectarse con Helicobacter pylori, en comparación con otros grupos sanguíneos $A B O$ (4). Otras infecciones, como las del virus de la hepatitis $B$, retrovirus, virus Chikungunya, tuberculosis, malaria, cólera y Escherichia coli, parecen estar determinadas por el grupo ABO de los sujetos infectados (5-7).

Los individuos de grupo $\mathrm{O}$ tienden a mostrar un riesgo inferior de enfermedad tromboembólica arterial y venosa, al poseer concentraciones hemáticas más bajos del factor de von Willebrand, involucrado en la cascada de coagulación. Mutaciones en el gen codificante del receptor de quimiocinas CCR5, se han asociado con resistencia a la infección por el virus de la inmunodeficiencia adquirida (VIH -1) (8). Algunos alelos del antígeno leucocitario humano (HLA) tienen efectos moduladores sobre la carga viral, especialmente para el virus de Epstein Barr, el VIH y la hepatitis C $(9,10)$, mientras que las deficiencias de interferones antivirales (IFN) causan enfermedades virales graves (11).

La predisposición genética de un individuo a padecer una determinada enfermedad ha sido planteada y descrita en afecciones de origen infeccioso como no infeccioso $(3,5,6)$. Como resultado de la diversidad étnica, existen diferencias poblacionales en la frecuencia alélica de marcadores genéticos que justificarían la heterogeneidad en la susceptibilidad y gravedad de ciertas afecciones.

Diversos estudios han evaluado la asociación entre biomarcadores del hospedero y la infección por coronavirus. En China, durante la epidemia por SARS-CoV-1, que causó el síndrome respiratorio agudo severo en el 2003 (12) y a principios de la pandemia por SARS-CoV-2 en el 2020, se observó que los sujetos de grupo sanguíneo O parecían mostrar un menor riesgo a infectarse que los individuos de otros grupos $\mathrm{ABO}(13,14)$.

Estudios observacionales y de asociación de genoma completo (GWAS, por sus siglas en inglés), coordinados por el COVID host genetics consortium (https://www.covid19hg. org/), y estudios de asociación de todo el transcriptoma (TWAS, por sus siglas en inglés) han confirmado la asociación entre diversos genes codificantes para proteínas involucradas en la interacción virus-hospedero y la infección por SARS-CoV-2 (15-17).

Uno de estos estudios identificó dos regiones significativamente asociadas con la forma grave de la infección, si bien el mecanismo exacto aún se desconoce (16). La primera, una región de aproximadamente 50 kilobases ubicada en el cromosoma 3, contiene seis genes (SLC6A20, LZTFL1, CCR9, FYCO1, CXCR6, XCR1) relacionados con proteínas que interactúan con el receptor para SARS-CoV-2 (ACE2, o enzima convertidora de angiotensina-2) y receptores de quimiocinas, controladores del tráfico de células efectoras en las vías respiratorias (16). La región mencionada, ubicada en locus 3p21.31, presente en aproximadamente $50 \%$ de los sujetos del sur de Asia y en el $16 \%$ de los europeos, probablemente herencia de los neandertales (18), es tal vez reflejo de adaptaciones de estas poblaciones fuera de África a enfermedades infecciosas durante el proceso evolutivo. La segunda región, ubicada en la banda 9q34.2 del cromosoma 9, incluye el locus $A B O$ y está significativamente asociada con una mayor gravedad 
en individuos infectados con SARS-CoV-2, específicamente en individuos con grupo sanguíneo A (OR 1.45, IC 95\%, $1.20-1.75)$ con respecto a los individuos con otros grupos $A B O$ (16), ratificando una potencial participación del sistema $\mathrm{ABO}$ en la susceptibilidad genética a la COVID-19.

Determinantes de la interacción patógeno-hospedero. El éxito y progresión de una infección viral hacia enfermedad clínica y su gravedad dependen de la interacción entre los factores de patogenicidad viral y la respuesta inmunitaria del hospedero, a su vez bajo la influencia de factores epigenéticos (Figura 1).

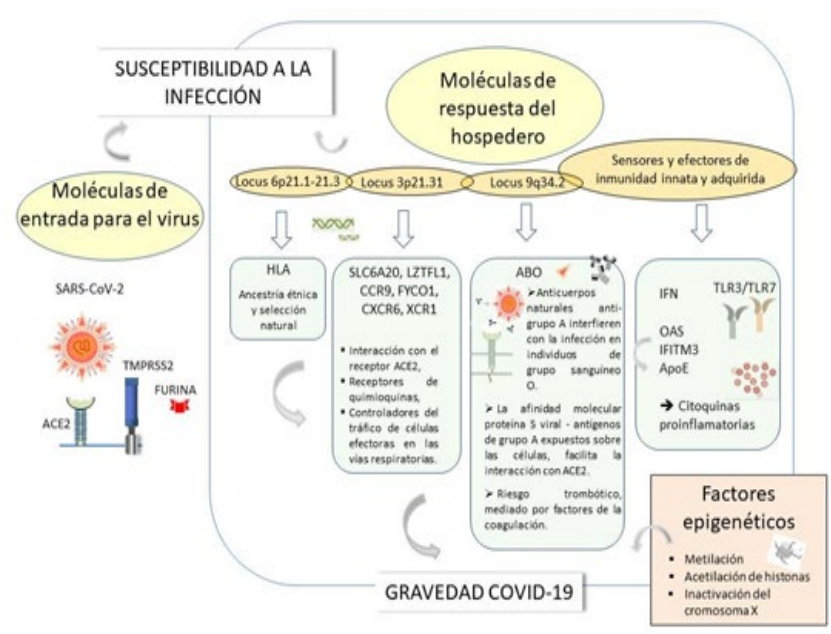

Figura 1. Representación esquemática de los factores que condicionan la compleja interacción virus-hospedero en la infección por SARS-CoV-2. Polimorfismos en los genes que codifican para las moléculas del hospedero que median la entrada del virus (receptor ACE2, TMPRSS2 y furina) y la respuesta inmunitaria innata y adquirida (sensores y efectores), definen el éxito y la progresión de la infección por SARS-CoV-2. Se plantea que anticuerpos naturales anti-grupo $A$ presentes en individuos de grupo sanguíneo $\mathrm{O}$, podrían interferir con la infección, bloqueando el antígeno $\mathrm{A}$ expresado en la membrana de origen celular de la envoltura viral, o los glicanos expuestos por la proteína $S$ del virus. En sujetos de grupo $A$, la afinidad molecular de la proteína $S$ hacia antígenos $A$ de las células blanco de las mucosas favorecería la interacción con el receptor ACE2, determinando mayor susceptibilidad. La cascada de señalización celular generada por la interacción de los antígenos virales con los sensores (TLR3/7) determina inducción de IFN y producción de citocinas proinflamatorias. Además, mecanismos epigenéticos pueden modificar la señalización de IFN, la expresión de ACE2 y la expresión de genes relacionados con la inmunidad (a través de la inactivación del cromosoma X). SARSCoV-2; Coronavirus-2 sindrome respiratorio agudo severo; ACE2, enzima convertidora de angiotesina-2; TMPRSS2, serina proteasa transmembrana 2; HLA, Antígenos Leucocitarios Humanos; IFN, interferon; TLRs: Toll like receptors; ABO: Antígenos de grupo sanguíneo; OAS: oligoadenilato sintetasa, CCR9, CXCR6, XCR1: receptores de quimiocinas; IFITM3: proteína transmembrana inducida por interferón 3; ApoE: apolipoproteína E. Vizzi E. 2021

Tanto las moléculas del hospedero que median la unión del virus SARS-CoV-2 con el receptor celular y la entrada al inicio de la infección, como la capacidad de respuesta innata y/ o adquirida del sistema inmunológico, juegan un papel clave en la fisiopatología de la progresión. Por otra parte, virus con diferentes mecanismos de evasión de la respuesta inmunitaria, pudieran ser potencialmente más infecciosos y condicionar la evolución del cuadro clínico (19).

1. Moléculas mediadoras de la unión y entrada del virus a la célula. Herramientas bioinformáticas han permitido inferir que las variantes genéticas de moléculas del hospedero que pueden alterar la interacción con el virus son poco frecuentes.

1.1. ACE2 y proteasas celulares: La infección por SARSCoV-2 depende de dos momentos claves, regulados por moléculas, una de las cuales es la enzima convertidora de angiotensina 2 (ACE2), receptor humano requerido para la invasión celular, y la otra, la serina proteasa transmembrana 2 (TMPRSS2) del hospedero, para el cebado de la proteína $S$ del virus (Figura 1). Las variaciones genéticas en éstas pueden potencialmente modular la predisposición genética de un individuo a la infección por el virus (20).

Los análisis genéticos del locus ACE2 en diversas poblaciones indican que se trata de una molécula altamente conservada con pocas variantes no sinónimas en el sitio de interacción con el dominio de unión al receptor del virus (RBD, por sus siglas en inglés) (21). Si bien variantes del gen ACE2 pueden alterar su expresión génica, conformación, estabilidad $y$, por ende, la afinidad por el virus, en la actualidad la evidencia sobre el tema es escasa y contradictoria.

No se describen diferencias significativas entre poblaciones (22-24), aunque su localización en el cromosoma $X$ ha sido relacionada con el mayor riesgo de letalidad por COVID-19 en el género masculino que en el femenino (2), si bien las tasas de infección son similares. Varios autores han descrito una expresión variable de ACE2 entre los tres grupos raciales principales del mundo (africanos, asiáticos y caucásicos), y entre órganos diferentes $(25,26)$. La heterogeneidad en la expresión de ACE2 entre diferentes grupos étnicos se ha atribuido a variaciones en la frecuencia alélica y expresión de loci de rasgos cuantitativos (27). Su menor expresión en el epitelio nasal, puerta de ingreso del virus, ha sido relacionada con la menor prevalencia de infección por SARS-CoV-2 en niños y jóvenes (28).

La actividad de las proteasas TMPRSS2 y furina, son cruciales para la entrada del virus a la célula. Si bien las variantes de actividad para la TMPRSS2 son raras (22), una expresión nasal significativamente más alta ha sido descrita en afrodescendientes americanos, denotando que pueden existir diferencias étnicas (29). A pesar de los intentos de correlacionar ciertas variantes de expresión del locus TMPRSS2 con una mayor gravedad de la COVID-19 en ciertas poblaciones, los resultados no han sido concluyentes, como tampoco para algunas variantes descritas en el gen de la furina $(20,24,30,31)$.

1.2. Polimorfismos $A B O$ : Evidencias crecientes sugieren que el grupo sanguíneo $A B O$ puede desempeñar un papel en la inmunopatogénesis de la infección por SARS-CoV-2 (17). Los antígenos de grupo sanguíneo $\mathrm{ABO}$ representan rasgos polimórficos heredados entre individuos y poblaciones. Estos oligosacáridos, sintetizados por la acción secuencial de glucosiltransferasas, expresados por los eritrocitos, 
también están presentes en secreciones mucosas y células epiteliales del tracto respiratorio y gastrointestinal, lugar donde el SARS-CoV se replica. Por tal motivo, se les conoce también como antígenos de grupo histo-sanguíneo (HBGA, por sus siglas en inglés).

Distintos estudios sugieren que los antígenos $A B O$ pueden actuar como factores innatos del hospedero, que influyen de manera diferencial en la susceptibilidad, de los individuos y sus descendientes, a determinadas infecciones entéricas pediátricas. Diferencias en la expresión de los antígenos ABO pueden aumentar o disminuir la susceptibilidad del hospedero a muchas infecciones (32). Se presume que puedan desempeñar un papel directo en la infección al actuar como receptores y/o correceptores de microorganismos, parásitos y virus, facilitar la captación intracelular, la transducción de señales o la adhesión a las superficies celulares a través de la organización de microdominios de membrana, interactuar con anticuerpos naturales y/o lectinas, o como inhibidores (por mimetismo molecular). Pueden actuar sobre el sistema inmunológico innato e influenciar la maduración del microbioma gastrointestinal $(5,33)$. Los antígenos ABO son, además, modificados por acción de la enzima $\alpha(1,2)$ fucosiltransferasa-2 (FUT2), y secretados en forma soluble en epitelios de individuos denominados "secretores". La FUT2, codificada por su respectivo gen ubicado en el locus 19q13, determina el estado secretor del grupo sanguíneo (5).

Las moléculas $\mathrm{ABO}$ han sido implicadas en la patogénesis de múltiples infecciones. Una cierta resistencia innata contra la infección entérica, causada por algunos NoV (3) y rotavirus de tipo $\mathrm{P}[4]$ y $\mathrm{P}[8](34,35)$, E. coli enterotoxigénica (ETEC) (36) y Campylobacter (37), ha sido atribuida a alelos no funcionales de FUT2 en individuos denominados "no secretores". Es posible que la capacidad de unión hacia moléculas $\mathrm{ABO}$, que se expresan en la superficie del epitelio gastrointestinal, difiera entre los patógenos, o entre cepas o tipos del mismo patógeno, afectando la entrada del agente causal y la infección (35).

Se plantea la posibilidad que la mayoría de los aislados humanos de SARS-CoV, así como del SARS-CoV-2, expresen HBGA en su envoltura viral, debido a la presencia de sitios de $\mathrm{N}$-glicosilación capaces de alojar glicanos de esa naturaleza, sintetizados en las mucosas. Durante la epidemia del 2003, Guillon y col. encontraron en un modelo experimental que los anticuerpos naturales o monoclonales anti-A inhibían específicamente la adhesión de células transfectadas que expresaban la proteína S de SARS-CoV a líneas celulares que poseían ACE2 (38). Basado en esto y en estudios epidemiológicos, se ha planteado la hipótesis que la interacción entre la proteína $S$ de SARS-CoV-2 y su receptor celular ACE2 podría ser obstaculizada por anticuerpos anti-grupo sanguíneo A naturalmente presentes en individuos de los grupos sanguíneos $\mathrm{O}$ y $\mathrm{B}$, justificando la menor susceptibilidad observada en los individuos del grupo $\mathrm{O}(32,38)$. Sin embargo, otros estudios argumentan que la etnicidad del grupo estudiado podría sesgar los resultados $(39,40)$.

Otras investigaciones sugieren que el tipo $\mathrm{ABO}$ condicionaría la gravedad de la COVID-19. Pacientes de grupo A, incluso de edad infantil, desarrollarían un cuadro clínico más grave que los de grupo $\mathrm{O}$, a causa probablemente del mayor riesgo cardiovascular y trombótico en sujetos de grupo $A(14,41)$.

2. Moléculas mediadoras de la respuesta del hospedero. Algunos polimorfismos de genes codificantes para componentes de la respuesta inmunitaria del hospedero han sido relacionados con variación interindividual en la gravedad a enfermedades respiratorias y a la COVID-19.

En la respuesta contra los virus respiratorios, el sistema inmunológico innato juega un papel clave, donde la cascada de señalización comienza con el reconocimiento de patrones moleculares asociados a patógenos (PAMPs) por los receptores de reconocimiento de patrones (PRR, del inglés patterns recognition receptors). Para los virus de ARN, los receptores tipo Toll (TLR) 3, 7 y 8, expresados en varios tipos celulares de pulmón, son PRR claves. Cada uno de estos receptores o sensores reconocen formas de ARN producidos por virus durante su proceso de infección (por ejemplo: ARN 5'-trifosfato, ARN bicatenario) y desencadenan una señalización descendente, que finalmente induce la traslocación de factores de transcripción al núcleo, estimulando la expresión de interferones de tipo I y III (IFN) y otras citocinas proinflamatorias. Una segunda ronda de señalización, autocrina y paracrina, asegura que las células infectadas y las no infectadas circundantes expresen una miríada de genes estimulados por interferón, que establecen el llamado estado antiviral, impidiendo la propagación de la infección y, desencadenando respuestas adaptativas para la eliminación del virus (42).

En un estudio que involucró dos parejas de hermanos menores de 35 años, de dos familias no emparentadas, con COVID-19 grave, se pudo identificar, a través de secuenciación del exoma completo y segregación familiar, dos variantes raras y putativas del gen del receptor Toll-like 7 (TLR7), localizado en el cromosoma X, la c.2129_2132del;p. [Gln710Argfs*18] y la c.2383G>T;p.[Val795Phe], las cuales determinaron una disminución en la expresión de TLR7, así como la alteración de la cascada de señalización descendente de la vía TLR7, con expresión disminuida de IRF7, IFNB1, ISG15 e IFN tipo II (IFN-y) (43). Esto indicaría que TLR7 es un componente esencial de la inmunidad innata frente a los coronavirus, incluido el SARS-CoV-2 (44), e incluso lo relacionan con la mayor mortalidad por COVID-19 observada en hombres que en mujeres (45). Otros estudios han revelado el papel esencial tanto de TLR3, sensor de ARN bicatenario, como de la inmunidad IFN tipo I intrínseca de la célula en el control de la infección por SARS-CoV-2 en los pulmones (46), Sin embargo, los loci críticos para la función de éstos sensores de ARN viral son bastantes conservados en todas las poblaciones, existiendo muy pocas variantes $(22)$.

EI SARS-CoV-2 induce una menor respuesta transcripcional antiviral, marcada por concentraciones bajas de IFN tipo I, una expresión elevada de quimiocinas y muy alta expresión de IL-6 en comparación con otros virus respiratorios. Esta respuesta sugiere que una reducción de las defensas antivirales innatas y una producción exacerbada de citocinas inflamatorias (IL-6, IL-1 $1 \beta$, TNF- $\alpha$ ) son los eventos que definen la enfermedad (47). Alteraciones en regiones

\section{Salus}


genómicas codificantes para la 2'5'oligoadenilato sintetasa (OAS), responsable de la degradación del ARN viral en respuesta a IFN, para la subunidad 2 del receptor $\alpha$ y $\beta$ (IFNAR2) o su expresión, o para receptores de quimiocinas CCR2, CCR9, CXCR6 y XCR1, parecen justificar variaciones interindividuales en casos críticos de COVID-19 $(16,31,48)$. Los estudios que sugieren el papel de los polimorfismos de los genes codificantes para las citocinas proinflamatorias, que conducen a desarrollo de daño alveolar grave e inflamación en la infección por SARS-CoV-2, se encuentran en desarrollo (49). Los polimorfismos que afectan la función y la expresión de la proteína transmembrana inducida por interferón 3 (IFITM3) pudiesen jugar un papel crucial en la capacidad antiviral de IFITM3. Se ha descrito una correlación entre la tasa de letalidad de COVID-19 y la frecuencia alélica del polimorfismo rs6598045 del gen de la IFITM3 (50).

Se ha planteado también que el alelo $A p o E$ e4e4 del gen de la apolipoproteína $E$ (ApoE), altamente coexpresada junto con el receptor ACE2 en los alveolos pulmonares de tipo II, incremente el riesgo de gravedad a la COVID-19, modulando las concentraciones de citocinas proinflamatorias (IL-6 y TNF- $\alpha$ ) (44).

La variabilidad y distribución geográfica de los antígenos leucocitarios humanos (HLA) se ha correlacionado con la incidencia de COVID-19, así como sucede con muchas otras enfermedades infecciosas (51). Genotipos específicos de HLA pueden estimular diferentes respuestas anti-virales mediadas por células $\mathrm{T}$, y podrían afectar progresión y transmisibilidad de la enfermedad (52). Un análisis de afinidad in silico de moléculas HLA clase 1, que incluyó 145 genotipos HLA-A, HLA-B y HLA-C, dirigido hacia 32.257 péptidos de SARS-CoV-2, reveló que los HLA-A*02:02, $-B^{*} 15: 03$ y $-C * 12: 03$ presentaban más eficientemente péptidos de SARS-CoV-2 altamente conservados y compartidos entre los coronavirus humanos comunes, y por tanto podían conferir protección. HLA-A*25:01, - $B * 46: 01$ y $-C^{*} 01: 02$, eran menos eficientes en su capacidad presentadora, sugiriendo que los individuos que albergan estos alelos pueden mostrar una respuesta inmunitaria débil y desarrollar síntomas más severos (53). Estudios en China demostraron una mayor frecuencia de alelos HLA-C*07:29 y $B^{*} 15: 27$ en pacientes con COVID-19 (54), mientras que los HLA-A*11:01, $B^{*} 51: 01$ y $C^{*} 14: 02$ predisponían a una enfermedad más severa (55). Lorente y col. Encontraron que la presencia de los alelos HLA-A*11, HLA-C*01 y HLA-DQB1*04 estaban asociados con mayor mortalidad (56). Por ende, algunos polimorfismos de los genes HLA ubicados en el brazo del cromosoma 6p21, podrían afectar la susceptibilidad a desarrollar COVID-19 grave e incrementar el riesgo de muerte de estos pacientes, si bien son necesarios estudios clínicos sistemáticos con poblaciones de mayor tamaño para esclarecer esta hipótesis.

Además se ha postulado que variantes de la proteína MBL2 (lectina de unión a manosa soluble), capaz de activar la ruta clásica del complemento, están asociadas con una mayor susceptibilidad al SARS-CoV (31).

3. Factores epigenéticos asociados a COVID-19. Los procesos que afectan el inicio de la transcripción genómica, así como el empaquetamiento del ADN en las células, pueden alterar la actividad y expresión de los genes (epigenoma) durante la interacción virus-hospedero. Se ha planteado que los mecanismos epigenéticos que incluyen metilación del $A D N$, acetilación de histonas e inactivación del cromosoma X pueden alterar el curso de la COVID-19, al regular la señalización de IFN, la expresión de ACE2 y los genes relacionados con la inmunidad. Así, la exposición a partículas ambientales, humo de cigarrillo y alérgenos, podrían determinar una expresión diferencial de ACE2 en el epitelio nasal, en directo contacto con el ambiente y sitio de entrada del SARS-CoV-2. Algunos estudios sugieren que la hipometilación de ACE2 en el epitelio nasal en sujetos masculinos de raza negra o en pacientes con Lupus, aumentaría la infectividad del SARS-CoV-2 y la gravedad de COVID-19 a través de una mayor abundancia de receptores ACE2 (57). La reducción de la actividad del promotor del gen de la superoxidodismutasa 3 (SOD3) causada por deacetilación histónica, podría explicar los cuadros más graves vistos en ancianos (20). Se ha planteado que la metilación de genes involucrados en la respuesta de IFN frente infecciones virales, modula la gravedad de la COVID-19 en pacientes sin comorbilidades (58).

\section{REFLEXIONES FINALES}

Los polimorfismos de algunos genes claves del hospedero involucrados en el mecanismo de entrada del SARSCoV-2 o en la respuesta inmunitaria, pueden modular la infectividad viral y/o la progresión de la enfermedad, bajo el efecto de factores ambientales. Si bien los estudios indican que las variaciones en los genes relacionados con las etapas tempranas de la infección por SARS-CoV-2 son poco comunes, la considerable variabilidad interindividual observada en la evolución de la enfermedad apunta hacia una naturaleza multifactorial de eventos.

En muchas infecciones virales se destaca la participación de: i) un componente innato, causado por la inactividad/ alteración de un gen para una proteína que interviene en las etapas tempranas de interacción virus-hospedero, que induce una diferente susceptibilidad a la infección, y ii) un componente adquirido, condicionado por la inmunidad virus-inducida, y la cascada de reacciones que a eso sigue, que define la evolución clínica. Los genes y sus respectivas variantes condicionan la actividad de los mediadores inflamatorios y antiinflamatorios, modulan la inmunidad, inflamación, apoptosis y posiblemente la senescencia celular. La naturaleza pleiotrópica de los componentes inmunológicos hace que la actividad pueda ser potencialmente compensada, derivando tal vez de allí la amplia variabilidad observada en los resultados de los estudios publicados.

Un reciente estudio de asociación de genoma completo (17) en el que se identificaron 13 loci independientes asociados a COVID-19, varios de ellos previamente documentados en enfermedades inflamatorias del pulmón o autoinmunes, encontró una asociación significativa del locus $A B O$ con susceptibilidad, mientras que otros loci estarían asociados con gravedad. Claramente, el curso clínico de la infección por SARS-CoV-2 es fuertemente dependiente de la relación entre el virus y el sistema inmunitario del hospedero, en el que los HLA y los TLR juegan un papel de activación y 
regulación central, y por ende en la patogenia inflamatoria de la COVID-19. Estudios dirigidos hacia marcadores genéticos o variantes para regiones no codificantes que alteran la expresión genética, contribuirían a definir mejor las diferencias interindividuales observadas entre pacientes infectados de la misma edad o sometidos a tratamiento médico similar. Cabe señalar que algunos factores sociodemográficos, la variante viral o las diferencias en los esquemas de vacunación, pueden influir en la susceptibilidad de un individuo a la infección por SARS-CoV-2 y la gravedad de la COVID-19.

La definición de los determinantes de susceptibilidad y gravedad para la COVID-19 permitiría seleccionar los pacientes mediante estratificación de riesgo sobre una base genética, identificar blancos terapéuticos y personalizar los tratamientos, diseñar estrategias de prevención mayormente eficaces y dirigidas hacia grupos a mayor riesgo, representando un paso determinante hacia el control de la pandemia.

\section{REFERENCIAS BIBLIOGRÁFICAS}

1. Zhou F, Yu T, Du R, Fan G, Liu Y, Liu Z, et al. Clinical course and risk factors for mortality of adult inpatients with COVID-19 in Wuhan, China: a retrospective cohort study. Lancet. 2020;395(10229):1054-1062.

2. Scully EP, Haverfield J, Ursin RL, Tannenbaum C, Klein SL. Considering how biological sex impacts immune responses and COVID-19 outcomes. Nat Rev Immunol. 2020;20(7):442447. https://doi.org/10.1038/s41577-020-0348-8

3. Lindesmith L, Moe C, Marionneau S, Ruvoen N, Jiang X, Lindblad L, et al. Human susceptibility and resistance to Norwalk virus infection. Nat Med. 2003;9(5):548-553.

4. Boren T, Falk P, Roth K, Larson G, Normark S. Attachment of Helicobacter pylori to human gastric epithelium mediated by blood group antigens. Science 1993;262:1892-1895

5. Cooling L. Blood groups in infection and host susceptibility. Clin Microbiol Rev. 2015;28(3):801-870.

6. Batool Z, Durrani SH, Tariq S. Association of $A B O$ and Rh blood group types to hepatitis $B$, hepatitis $C$, HIV and syphilis infection, a five year' experience in healthy blood donors in a tertiary care hospital. J Ayub Med Coll Abbottabad. 2017;29(1):90-92

7. Fumagalli M, Cagliani R, Pozzoli U, Riva S, Comi GP, Menozzi $G$, et al. Widespread balancing selection and pathogendriven selection at blood group antigen genes. Genome Res. 2008;19(2):199-212.

8. Quillent C, Oberlin E, Braun J, Rousset D, Gonzalez-Canal $G$, Métais $P$, et al. HIV-1 resistance phenotype conferred by combination of two separate inherited mutations of CCR5 gene. Lancet. 1998; 351(9095):14-18.

9. Agostini S, Mancuso R, Guerini FR, D'Alfonso S, Agliardi C, Hernis A, et al. HLA alleles modulate EBV viral load in multiple sclerosis. J Transl Med [Internet]. 2018;16(1):1-9.

10. Julg B, Moodley ES, Qi Y, Ramduth D, Reddy S, Mncube Z, et al. Possession of HLA class II DRB1*1303 associates with reduced viral loads in chronic HIV-1 clade $\mathrm{C}$ and $\mathrm{B}$ infection. $J$ Infect Dis. 2011;203(6):803-809.

11. Lim HK, Huang SXL, Chen J, Kerner G, Gilliaux O, Bastard P, et al. Severe influenza pneumonitis in children with inherited TLR3 deficiency. J Exp Med. 2019;216(9):2038-2056.
12. Cheng $\mathrm{Y}$, Cheng G, Chui $\mathrm{CH}$, Lau FY, Chan PKS, Ng MHL, et al. $A B O$ blood group and susceptibility to severe acute respiratory syndrome. JAMA 2005; 293(12):1450-1451.

13. Zhao J, Yang Y, Huang H, Li D, Gu D, Lu X, et al. Relationship between the $\mathrm{ABO}$ blood group and the Coronavirus Disease 2019 (COVID-19) susceptibility. Clin Infect Dis. 2021;73(2):328-331

14. Li J, Wang X, Chen J, Cai Y, Deng A, Yang M. Association between $\mathrm{ABO}$ blood groups and risk of SARS-CoV-2 pneumonia. Br J Haematol. 2020;190(1):24-27.

15. Jahanafrooz Z, Chen Z, Bao J, Li H, Lipworth L, Guo X. An overview of human proteins and genes involved in SARSCoV-2 infection. Gene. 2022 15;808:145963. https://doi. org/10.1016/j.gene.2021.145963.

16. Severe Covid-19 GWAS Group, Ellinghaus D, Degenhardt $F$ Bujanda L, Buti M, Albillos A, Invernizzi P, et al. Genomewide association study of severe Covid-19 with respiratory failure. N Engl J Med. 2020 Oct 15;383(16):1522-1534. https://doi. org/10.1056/NEJMoa2020283

17. COVID-19 Host Genetics Initiative. Mapping the human genetic architecture of COVID-19. Nature 2021; 600(7889): 472-477. https://doi.org/10.1038/s41586-021-03767-x

18. Zeberg $H$, Pääbo $S$. The major genetic risk factor for severe COVID-19 is inherited from Neanderthals. Nature [Internet]. 2020;587(7835):610-612. https://doi.org/10.1038/s41586020-2818-3.

19. Bakhshandeh B, Jahanafrooz Z, Abbasi A, Goli MB, Sadeghi M, Mottaqi MS, et al. Mutations in SARS-CoV-2; Consequences in structure, function, and pathogenicity of the virus. Microb Pathog. 2021;154:104831. https://doi.org/10.1016/j. micpath.2021.104831.

20. Yildirim Z, Sahin OS, Yazar S, Bozok Cetintas V. Genetic and epigenetic factors associated with increased severity of Covid-19. Cell Biol Int. 2021;45(6):1158-1174.

21. Lan J, Ge J, Yu J, Shan S, Zhou H, Fan S, et al. Structure of the SARS-CoV-2 spike receptor-binding domain bound to the ACE2 receptor. Nature. 2020;581(7807):215-220.

22. Lee IH, Lee JW, Kong SW. A survey of genetic variants in SARSCoV-2 interacting domains of ACE2, TMPRSS2 and TLR3/7/8 across populations. Infect Genet Evol. 2020;85:104507. https:// doi.org/10.1016/j.meegid.2020.104507

23. Lopera Maya EA, van der Graaf A, Lanting $P$, van der Geest $\mathrm{M}, \mathrm{Fu} \mathrm{J}$, Swertz M, et al. Lack of association between genetic variants at ACE2 and TMPRSS2 genes involved in SARSCoV-2 infection and human quantitative phenotypes. Front Genet. 2020;11:1-10.

24. Asselta R, Paraboschi EM, Mantovani A, Duga S. ACE2 and TMPRSS2 variants and expression as candidates to sex and country differences in COVID-19 severity in Italy. Aging (Albany NY). 2020;12(11):10087-10098. https://doi.org/10.18632/ aging. 103415.

25. Choudhary S, Sreenivasulu K, Mitra P, Misra S, Sharma P. Role of genetic variants and gene expression in the susceptibility and severity of COVID-19. Ann Lab Med. 2020;41(2):129-138. https://doi.org/10.3343/alm.2021.41.2.129.

26. Chen J, Jiang Q, Xia X, Liu K, Yu Z, Tao W, et al. Individual variation of the SARS-CoV-2 receptor ACE2 gene expression and regulation. Aging Cell. 2020;19(7):1-12.

27. Cao Y, Li L, Feng Z, Wan S, Huang P, Sun X, et al. Comparative genetic analysis of the novel coronavirus (2019-nCoV/SARSCoV-2) receptor ACE2 in different populations. Cell Discov. 2020;6(1):4-7. 
28. Bunyavanich S, Do A, Vicencio A. Nasal gene expression of angiotensin-converting enzyme 2 in children and adults. JAMA. 2020;323(23):2427-2429. https://doi.org/10.1001/ jama.2020.8707

29. Bunyavanich S, Grant C, Vicencio A. Racial/Ethnic Variation in nasal gene expression of transmembrane serine protease 2 (TMPRSS2). JAMA - J Am Med Assoc. 2020;324(15):15671568. https://doi.org/10.1001/jama.2020.17386.

30. Bhattacharyya C, Das C, Ghosh A, Singh AK, Mukherjee $\mathrm{S}$, Majumder PP, et al. Global spread of Sars-coV2 subtype with spike protein mutation D614G is shaped by human genomic variations that regulate expression of TMPRSS2 and Mx1 genes. BioRxiv 2020.05.04.075911; https://doi. org/10.1101/2020.05.04.075911

31. Klaassen K, Stankovic B, Zukic B, Kotur N, Gasic V, Pavlovic $S$, et al. Functional prediction and comparative population analysis of variants in genes for proteases and innate immunity related to SARS-CoV-2 infection. Infect Genet Evol. 2020;84: 104498. https://doi.org/10.1016/j.meegid.2020.104498

32. Goel R, Bloch EM, Pirenne F, Al-Riyami AZ, Crowe E, Dau L, et al. $A B O$ blood group and COVID-19: a review on behalf of the ISBT COVID-19 Working Group. Vox Sang. 2021;116(8):849861.

33. Fumagalli M, Cagliani R, Pozzoli U, Riva S, Comi GP, Menozzi $G$, et al. Widespread balancing selection and pathogendriven selection at blood group antigen genes. Genome Res. 2009;19(2):199-212.

34. Zhang XF, Long $Y$, Tan $M$, Zhang $T$, Huang $Q$, Jiang $X$, et al. $P[8]$ and $P[4]$ Rotavirus infection associated with secretor phenotypes among children in South China. Sci Rep. 2016;6:34591. https://doi.org/10.1038/srep34591.

35. Nordgren J, Sharma S, Bucardo F, Nasir W, Günaydin G, Ouermi D, et al. Both lewis and secretor status mediate susceptibility to rotavirus infections in a rotavirus genotypedependent manner. Clin Infect Dis. 2014;59(11):1567-1573.

36. Mottram L, Wiklund G, Larson G, Qadri F, Svennerholm AM. FUT2 non-secretor status is associated with altered susceptibility to symptomatic enterotoxigenic Escherichia coli infection in Bangladeshis. Sci Rep. 2017;7(1):10649. https:// doi.org/10.1038/s41598-017-10854-5.

37. Ruiz-Palacios GM, Cervantes LE, Ramos P, ChavezMunguia B, Newburg DS. Campylobacter jejuni binds intestinal $\mathrm{H}(\mathrm{O})$ antigen (Fuca1, 2Galß1, 4GIcNAc), and fucosyloligosaccharides of human milk inhibit its binding and infection. J Biol Chem [Internet]. 2003;278(16):14112-14120.

38. Guillon P, Clément M, Sébille V, Rivain JG, Chou CF, RuvoënClouet N, et al. Inhibition of the interaction between the SARSCoV spike protein and its cellular receptor by anti-histo-blood group antibodies. Glycobiology. 2008;18(12):1085-1093.

39. Levi JE, Telles PR, Scrivani H, Campana G. Lack of association between ABO blood groups and susceptibility to SARS-CoV-2 infection. Vox Sang. 2021;116(2):251-252.

40. Dzik S, Eliason K, Morris EB, Kaufman RM, North CM. COVID-19 and $A B O$ blood groups. Transfusion. 2020;60(8):1883-1884.

41. Bari A, Ch A, Hareem S, Bano I, Rashid J, Sadiq M. Association of blood groups with the severity and outcome of covid-19 infection in children. J Coll Physicians Surg Pakistan. 2021;31:S57-59.

42. Kikkert M. Innate immune evasion by human respiratory RNA viruses. J Innate Immun. 2020;12(1):4-20.
43. Van Der Made Cl, Simons A, Schuurs-Hoeijmakers J, Van Den Heuvel G, Mantere T, Kersten S, et al. Presence of genetic variants among young men with severe COVID-19. JAMA - J Am Med Assoc. 2020;324(7):663-673.

44. Anastassopoulou C, Gkizarioti Z, Patrinos GP, Tsakris A. Human genetic factors associated with susceptibility to SARS-CoV-2 infection and COVID-19 disease severity. Hum Genomics. 2020;14(1):1-8.

45. Schurz H, Salie M, Tromp G, Hoal EG, Kinnear CJ, Möller $M$. The $X$ chromosome and sex-specific effects in infectious disease susceptibility. Hum Genomics. 2019;13(1):2. https:// doi.org/10.1186/s40246-018-0185-z.

46. Zhang Q, Liu Z, Moncada-Velez M, Chen J, Ogishi M, Bigio B, et al. Inborn errors of type I IFN immunity in patients with lifethreatening COVID-19. Science 2020;370(6515):eabd4570. https://doi.org/10.1126/science.abd4570.

47. Blanco-Melo D, Nilsson-Payant BE, Liu WC, Uhl S, Hoagland D, Møller R, et al. Imbalanced host response to SARS-CoV-2 drives development of COVID-19. Cell. 2020;181(5):1036-1045.e9.

48. Pairo-Castineira E, Clohisey S, Klaric L, Bretherick AD, Rawlik K, Pasko D, et al. Genetic mechanisms of critical illness in COVID-19. Nature. 2021;591(7848):92-98.

49. Kadkhoda K. COVID-19: an Immunopathological View. mSphere. 2020;5(2):19-22.

50. Kim YC, Jeong $\mathrm{BH}$. Strong correlation between the case fatality rate of covid-19 and the rs6598045 single nucleotide polymorphism (SNP) of the interferon-induced transmembrane protein 3 (IFITM3) gene at the population-level. Genes (Basel). 2021;12(1): 2021;12(1):42. https://doi.org/10.3390/ genes12010042

51. Tavasolian F, Rashidi M, Hatam GR, Jeddi M, Hosseini AZ, Mosawi SH, et al. HLA, Immune response, and susceptibility to COVID-19. Front Immunol 2021;11:601886. https://doi. org/10.3389/fimmu.2020.6

52. Initiative C-19 HG. The COVID-19 Host Genetics Initiative, a global initiative to elucidate the role of host genetic factors in susceptibility and severity of the SARS-CoV-2 virus pandemic. Eur J Hum Genet. 2020;28(6):715-718.

53. Nguyen A, David JK, Maden SK, Wood MA, Weeder BR, Nellore $A$, et al. Human leukocyte antigen susceptibility map for SARS-CoV-2. J Virol [Internet]. 2020;94(13):1-12.

54. Wang W, Zhang W, Zhang J, He J, Zhu F. Distribution of HLA allele frequencies in 82 Chinese individuals with coronavirus disease-2019 (COVID-19). Hla. 2020;96(2):194-196.

55. Wang F, Huang S, Gao R, Zhou Y, Lai C, Li Z, et al. Initial whole-genome sequencing and analysis of the host genetic contribution to COVID-19 severity and susceptibility. Cell Discov [Internet]. 2020;6(1). http://dx.doi.org/10.1038/s41421020-00231-4

56. Lorente L, Martín MM, Franco A, Barrios Y, Cáceres JJ, SoléViolán J, et al. HLA genetic polymorphisms and prognosis of patients with COVID-19. Med Intensiva. 2021;45(2):96-103.

57. Cardenas A, Rifas-Shiman SL, Sordillo JE, DeMeo DL, Baccarelli AA, Hivert MF, et al. DNA methylation architecture of the ACE2 gene in nasal cells of children. Sci Rep [Internet]. 2021;11(1):1-9. https://doi.org/10.1038/s41598-021-86494-7

58. Castro de Moura M, Davalos V, Planas-Serra L, Alvarez-Errico D, Arribas C, Ruiz M, et al. Epigenome-wide association study of COVID-19 severity with respiratory failure. EBioMedicine. 2021;66:1-10. 